\title{
KEEPING PHYSICIAN'S PROFESSIONAL COMPETENCE CURRENT AND RELEVANT TO MODERN PRACTICE: THE NEED FOR LIFELONG LEARNING
}

\author{
Oksana Dudina \\ Ph.D., Lecturer, Donetsk National Medical University, Ukraine \\ e-mail: rexiff@ukr.net,orcid.org/0000-0003-0405-5837
}

\section{Summary}

The article describes main features of continuing professional medical education in contemperory world influenced by the pandemic COVID-19. The aim of the research is to study the basics of management of the effectiveness of doctors and paramedics training based on lifelong learning. A new model of a healthcare professional competence is reviwed in the article. The analytical method was used as a research method while analyzing scientific and pedagogical literature. The prospective development of modern medicine is impossible without continuous medical education, which dynamically encompasses not only the majority of scientific disciplines, but also a multifaceted spectrum of innovative technologies. The proposed key directions of management of the effectiveness of doctor's training in the COVID-19 situation are based on the main principles of the implementation of the concept of medical lifelong learning. At the present stage of healthcare system in Ukraine a lot of qualified professionals in many specific specialties are needed. The country also needs creative individuals who are able to acquire the necessary professional competences through lifelong education.

Keywords: continuous education, medical education, health professionals, physician's competence, professionalism.

DOI: https://doi.org/10.23856/4209

\section{Introduction}

Emergencies in healthcare such as the COVID-19 outbreak are a major challenge for doctors providing medical treatment and now require powerful well-developed and advanced skills to respond effectively to such urgent situations.

Currently, one of the most relevant issues for the medical community is the question of the need to enter the system of continuous medical education in order to pass the subsequent procedure for the accreditation of a specialist. After analyzing the Australian scientific research done by Z. S. Siddiqui in «Lifelong learning in medical education: From CME to CPD», we came to the conclusion that lifelong learning is a concept taken up by governments and educational institutions worldwide to acknowledge the need for continuous learning irrespective of the profession. In the context of medicine, lifelong learning has always been formally considered an ethical obligation of doctors although the term Continuing Medical Education (CME) is more commonly used than Continuous Professional Development (Siddiqui, 2003: 44). Many Ukrainian doctors had previously found an opportunity to improve their skills - through grants, partnership programs, their own funds or private clinics, if they worked there.

The problem of lifelong learning of physicians becomes especially relevant in the circumstatces with COVID-19. Critical care medicine plays a crucial role in urgent situations. 
The works of such world-famous scientists (R. A. Foullon, J. R. Combes, E. Arespacochaga, T. Horsley, J. Grimshaw, C. Campbell, A. Wallman, C. Vaudan, S. K. Sporrong and others) are devoted to the concept of doctor's professional competence. The issues and conditions of lifelong learning along the education and career continuum were risen in the articles of O. Babenko, S. Koppula, L. Daniels, L. Nadon, V. Daniels, M. Ding, A. Oswald, J. White and etc.).

The purpose of our research is the consideration of the basics of management of the effectiveness of medical workers training based on lifelong learning.

\section{Professionalism as a key concept of medical education}

The important aspects of doctor's professionalism are mastering the ethics standards of professionals, respecting patients and doing professional activity for improving the patient's health regardless of his gender, nationality, religion and social status. The Canadian researchers of University of Alberta, M. Ding, O. Babenko, S. Koppula, A. Oswald, J. White, in their work «Physicians as Teachers and Lifelong Learners» state that physicians who experienced greater psychological need satisfaction at work and those who were involved in clinical teaching had, on average, higher lifelong learning scores, so, physician lifelong learning had significant associations with life satisfaction and teaching enjoyment but not with stress level and burnout frequency (Ding, Babenko, Koppula, Oswald, White, 2019: 5).

The report of Royal College of Physicians «Advancing medical professionalism» made by J. Tweedie, J. Hordern, J. Dacre focuses on seven key aspects of professional practice: 1) doctor as healer, 2) patient partner, 3) team worker, 4) manager and leader, 5) learner and teacher, 6) advocate, 7) innovator (Tweedie, Hordern, Dacre, 2018: 6).

The whole world watched the professionalism of Chinese doctors, especially in treating patients and quick reaction on COVID-19. The famous researchers Ch. R. Stephenson, Q. Qian, P. S. Mueller, D. C. Schlek, J. N. Mandrekar, T. J. Beckman, and Ch. M. Wittich introduced the results of their investigation in the work «Chinese physician perceptions regarding industry support of continuing medical education programs: a cross-sectional survey». They had an aim to determine perceptions regarding industry support for CME among Chinese physicians at a large CME course, examine potential associations between Chinese physicians' perceptions and their demographic characteristics, and compare Chinese and US physicians' perceptions of industry support for CME (Stephenson, Qian, Mueller, Schlek, Mandrekar, Beckman \& Wittich, 2020). They made a conclusion that Chinese continuing medical education participants preferred industry-sponsored continuing medical education and were strongly in favour of industry offsetting costs, but almost half believed that such education was biased in favour of supporting companies.

T. Horsley, J. Grimshaw and C. Campbell point out that discordance between the expectations of patients and the abilities of physicians are prompting the profession to strengthen assertions of «professionalism»; to increase accountability, compulsory engagement in continuing professional development (CPD) systems or programmes can be considered (Horsley, Grimshaw \& Campbell, 2010: 4).

Scientist O. Babenko, S. Koppula, L. Daniels, L. Nadon, V. Daniels in the work «Lifelong learning along the education and career continuum: meta-analysis of studies in health professions» recognized lifelong learning as an indicator of professionalism, competence, and critical competent of continuing professional development. Despite this, there has been a paucity of validated tools to assess lifelong learning, with most measuring attitudes and beliefs toward lifelong learning rather than demonstrated behaviours and skills (Babenko, Koppula, Daniels, Nadon, Daniels, 2017: 157). 


\section{The management of the effectiveness of physicians' training in the COVID-19 conditions}

Mastering the professional competence of a physician acquired at the end of bachelor's training and postgraduate professional medical education is not enough to provide competence and efficiency in the career. Future doctors are expected effectively participate in lifelong learning strategies. A Ukrainian doctor must be certified every five years to confirm his professional competence necessary for the doctor's category, or to be awarded with a higher category that determines the doctor's salary. A year before the certification, the doctor must attend mandatory courses, the so-called pre-certification cycle. The doctor follows the advanced four weeks training course in a special medical institution. Actually, it is the end of the mandatory professional development of the doctor, all other courses, seminars and workshops are attended by doctors' own initiative. Canadian scientists T. Horsley, J. Grimshaw and C. Campbell in their work «How to create conditions for adapting physicians' skills to new needs and lifelong learning» stress out that through participation in organized continuing education programmes or through individual learning activities health care professionals are expected to remain current in their practice through efficient knowledge-management practices (evidence informed practice) and self-directed learning strategies (lifelong learning) (Horsley, Grimshaw \& Campbell, 2010: 3).

The model of medical education is largely determined with two components: the accreditation of a specialist and the introduction of continuing medical education. Moreover, the accreditation of a specialist becomes necessary in the procedure for admission to professional activity, and continuing medical education is a condition for a specialist to undergo the accreditation procedure.

Chinese researchers, L. Li, Q. Xv and J. Yan, in the article «COVID-19: the need for continuous medical education and training» report that standardised training such as that provided by the $5 \mathrm{C}$ programme helps in the development of critical-care medicine disciplines and improves the clinical level of practitioners. That means that teams are better prepared to deal with health emergencies in the ICU $(L i, X v, \&$ Yan, 2020).

However, the training of qualified medical practitioners in seminars within the framework of thematic or certification cycles has practically no effect on their knowledge and critical assessment skills. Perhaps this is because both training and control are not mandatory components in the system of existing continuing professional education. This may also be because training is insufficient in time, too superficial, is stereotyped, too passive, far from practice and does not take into account the methodology of adult education.

The effectiveness of the educational process of doctors for improving the knowledge in the COVID-19 treatment, along with the solution of general organizational issues, largely depends on the level of the current educational and organizational activities of the department. It includes the acquisition of cycles, methodological and organizational support of the training classes in COVID-19 and the formation of reports at the institutions.

Highly qualified medical workers do not appear immediately after completing the education program in the university (see Fig. 1), but constantly in the process of formation, their professional activity requires continuous dynamics, self-improvement and self-realization through cooperation with professionals, continuous training and reflection of their skills. Doctors also need to understand the meaning of their work and its potential, as healthcare is not like any other activity. Experience plays a significant role in the delicate process of healthcare and patients' treatment. 


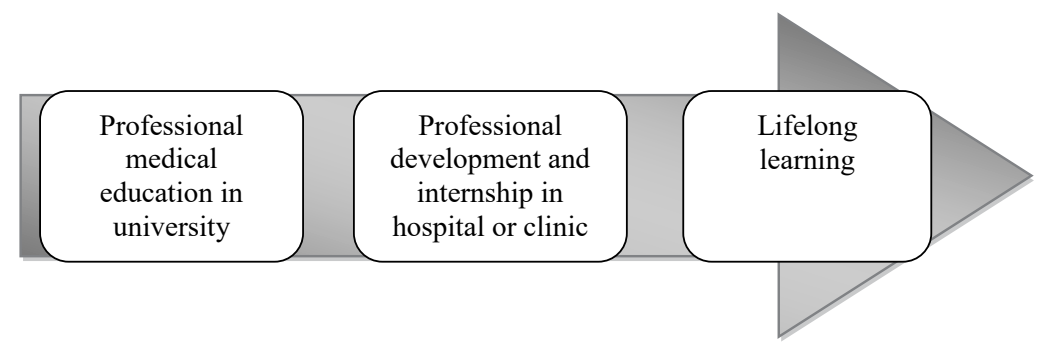

Fig. 1. Continuity of professional training of physicians

Training in accordance with the principles of continuing medical education using distance learning technologies has both positive and negative aspects of this training of doctors. At the same time, it is not proved that distance education will gradually replace traditional, but only supplement it and expand its possibilities. Distance learning presupposes that students have some initial knowledge, including in relation to skills of working in the Internet. Therefore, it is possible for distance lifelong learning of doctors to improve their competence in the COVID-19 treatment. It is also necessary to provide appropriate technical support for the participants in the educational process (at the departments/hospitals/clinics). Therefore, the elements of distance learning can be only used in cycles for advanced users, masters and graduate students.

\section{Conclusions}

The educational programs for advanced training and doctors' accreditation should be implemented aimed at improving existing or mastering new skills and abilities within the framework of the employee's qualifications, mastering new knowledge of skills and abilities with the assignment of new qualifications. Ukraine needs the designed educational programs and distance educational modules for the most relevant prevention, diagnosis and treatment of socially significant diseases, especially COVID-19 disease that have a major impact on the morbidity and mortality of the population.

After analyzing scientific works of world-famous scholars and researchers, we can differentiate the key directions in management of the effectiveness in doctor's training in the situation with COVID-19 that are based on the main principles of the implementation of the concept of continuing medical education. They are as follows: 1 ) an increase of number of organizations implementing additional professional programs to improving physicians' education for treatment and stop spread of COVID-19; 2) expansion and concretization of the types of additional educational programs regulated by law, which are associated with opportunistic transformations in the educational services market and the need of continuous updating of educational programs and services in general; 3) continuing professional education in medicine should be considered as a system that is a part of the overall totality with the economy and the labour market, in which a reverse connection should take place: educational institution-organization, which will allow to create innovative and relevant educational programs that meet labour market demands, social requirements, international standards. 


\section{References}

Babenko O., Koppula S., Daniels L., Nadon L., \& Daniels V. (2017) Lifelong learning along the education and career continuum: meta-analysis of studies in health professions. Journal of Advances in Medical Education \& Professionalism, no. 5(4), pp. 157-163. Retrieved from: https://europepmc.org/article/pmc/pmc5611424

Ding M., Babenko O., Koppula S., Oswald A., \& White J. (2019) Physicians as Teachers and Lifelong Learners. Journal of Continuing Education in the Health Professions, no. 39(1), pp. 2-6. Retrieved from: https://journals.lww.com/jcehp/Abstract/2019/03910/Physicians_as_ Teachers_and_Lifelong_Learners.2.aspx doi: 10.1097/CEH.0000000000000228

Horsley $\bar{T}$., Grimshaw J., \& Campbell C. (2010) How to create conditions for adapting physicians'skills to new needs and lifelong learning. WHO Regional Office for Europe and European Observatory on Health Systems and Policies. Retrieved from: https://www.euro.who. int/_data/assets/pdf_file/0020/124418/e94294.pdf

Li L., Xv Q., \& Yan J. (2020) COVID-19: the need for continuous medical education and training. The Lancet. Respiratory Medicine, no. 8(4). Retrieved from: https://www.thelancet.com/journals/lanres/article/PIIS2213-2600(20)30125-9/fulltext doi: 10.1016/S2213-2600(20)30125-9

Siddiqui, Z. S. (2003) Lifelong learning in medical education: From CME to CPD. Journal of the College of Physicians and Surgeons-Pakistan, no. 13(1), pp. 44-47. Retrieved from: https://www.researchgate.net/publication/10813206_Lifelong_ learning_in_medical_education_From_CME_to_CPD

Stephenson, Ch. R., Qian, Q., Mueller, P. S., Schlek, D. C., Mandrekar, J. N., Beckman, T. J $\&$ Wittich, Ch. M. (2020) Chinese physician perceptions regarding industry support of continuing medical education programs: a cross-sectional survey. Medical Education Online, 25. Retrieved from: https://www.tandfonline.com/doi/full/10.1080/10872981.2019.1694308 doi: 10.1080/10872981.2019.1694308

Tweedie, J., Hordern, J., \& Dacre, J. (2018) Advancing medical professionalism. London: Royal College of Physicians. Retrieved from: https://www.rcplondon.ac.uk/projects/outputs/ advancing-medical-professionalism 